\title{
8 Global Mindset as the Integration of Emerging Socio-Cultural Values Through Mindsponge Processes
}

\author{
A Transition Economy Perspective ${ }^{1}$
}

\author{
Quan Hoang Vuong
}

\section{Introduction}

A flat (Friedman 2005) or spiky (Florida 2005) world does not matter, as globalization has passed the point of no return. Much of the international recognition for an emerging economy, therefore, rests with its cultural relevance to its economic partners worldwide. Active participation on the global scale has made acculturation more apparent and faster today, especially for managers working in multicultural environments (Gupta \& Govindarajan 2002). In other words, managers with global mindsets are presumably more open in their thinking (Taylor 1991), which in turn enables them to make use of serendipity as a strategic advantage (Napier \& Vuong 2013b).

Meanwhile, businesspeople are facing an emerging problem of getting so very many cultural values. A framework for assessing the values may help them improve their ability to respond not only faster, but also more efficiently to a new cultural setting. Last but not least, a fast-changing world renders it possible to make a proper values today inappropriate tomorrow and vice versa. It is, therefore, necessary to keep value evaluation as well as learning/unlearning processes continuous.

This chapter proposes the concept of the mindsponge and its underlying themes that explain why and how executives, managers, and corporations could replace waning values in their mindsets with those absorbed during their exposure to multicultural and global settings. One can think of a mindsponge as a metaphor of the mind as a sponge that squeezes out inappropriate values and absorbs new ones that fit or complement the context at hand.

This chapter first provides a brief literature review on global mindset and cultural values, which suggests that not only can a mindset be improved, but that its learning mechanism can also be developed. Then the chapter offers a conceptual framework, called the "mindsponge," which builds upon earlier works linking mindset to themes of multi-filtering (e.g., Vuong \& Napier $2013,2014)$. The process is proposed to help identify emerging values in the transition economy of Vietnam and also to reconfirm existing core values. Discussions about (i) serendipity as a method of innovation, (ii) pursuit of 


\section{Quan Hoang Vuong}

creative performance, and (iii) trust as a process of building confidence and reliability are illustrated by practical applications of the mindsponge and real-life business evidence provided by an inclusive corporate innovation survey (the i2Metrix).

\section{Literature Review}

There are several works—such as Berry (1983, 1997), Dweck (2006), Levy, Beechler, Taylor, \& Boyacigilier (2007), and Maznevski \& Lane (2007)— that suggest that not only a mindset but also its learning mechanism can be developed to meet business management's need for strengthening competitiveness while the world economy is entering an unchartered territory. When arguing for a global mindset-which consists of core cultural values that are appropriate to a global setting-it should be open to the replacement of waning values. Therefore, the authors also raise the need for learning more about the values. For this purpose, this section reviews selected related literature on improving a global mindset and the cultural values that emerge in the improvement process.

\subsection{Global Mindset}

Goldstein \& Brooks (2007) define mindset as assumptions and expectations that people hold about themselves and others. That is, one's mindset consists of [cultural] values defining the individual. Although such a definition suggests a limited and stable set of values, many-for instance, Gupta \& Govindarajan (2002), Dweck (2006), and Levy et al. (2007)—argue that a mindset can be changed and even grown in order to adapt to the changing environment. Dweck (2006) claims that a mindset can be either fixed and/ or growth oriented, but does not say explicitly that one should separate one type of mindset from another. In other words, a mindset consists of fixed and growth areas. The former focuses on developing a certain ability, while the latter is interested in new abilities. Indeed, Dweck introduces practices to train a growth mindset but does not explain how the two mindsets may interact with and affect each other.

Gupta \& Govindarajan (2002) regard global mindset as a crucial factor for success in exploiting opportunities in a dynamic world of globalization. Also, Boyd \& Richerson (1985) suggest that confidence in a particular belief may grow if many others with whom the individual has come into contact also share such a belief. Inconsistent information is either rejected or may be a reason to initiate changes in the mindset.

Levy et al. (2007) offer two major approaches to the conceptualization of global mindset: (i) a cultural perspective that focuses on cultural diversity and distance, and (ii) a strategic perspective that focuses on [business] 
environmental complexity and strategic variety. Cosmopolitanism is the underlying theme of the former, while cognitive complexity characterizes the latter. A third approach, the multidimensional perspective, combines the two.

Among researchers who support the notion of information processing as being critical to building a global mindset, Rhinesmith (1992, 1993, 1996) takes a practitioner approach. He defines global mindset as the ability to scan the world (i.e., process information) from a broad perspective and to find unexpected trends and opportunities to achieve organizational as well as individual goals. The definition, therefore, incorporates not only the cultural and strategic perspectives, but also individual characteristics. Pisapia, Reyes-Guerra, \& Coukos-Semmel (2005) argue that leaders need a strategic mindset, which can be developed by advanced cognitive processes. In addition, a global mindset can be improved by education (e.g., Maznevski \& Lane 2007). Building knowledge and skills is critical, but Maznevski and Lane argue that the development of a global mindset incorporates: (i) building a comprehensive cognitive structure that guides the process of information selection and processing, and (ii) building a capability for constantly updating this cognitive structure once exposed to new experiences. Muzychenko (2007) also suggests that a global mindset can be enhanced through a formal education, especially for entrepreneurs to develop competencies that allow them to exploit opportunities presented by globalization.

From a cultural perspective, a global mindset consists of "self-awareness, openness to and understanding of other cultures, and selective incorporation of foreign values and practice" (Levy et al. 2007, p.6). The strategic perspective of a global mindset (Levy et al. 2007) has emerged in part because of the complexity of globalization itself. Several scholars argue that globalization is so complex that structural means and administrative mechanisms (Chandler 1962) are now insufficient for multinational corporations (MNCs) to mitigate environmental and organizational complexity (Prahalad \& Bettis 1986; Doz \& Prahalad 1991; Evans, Pucik \& Barsoux 2002). In light of this, the strategic perspective suggests that MNCs need a global and strategic mindset to compete successfully (Bartlett \& Ghoshal 1989; Caproni, Lenway \& Murtha 1992).

While academics and managers are reaching a consensus on the pivotal role of a global mindset, the "flat world" of information challenges them. The competitive pressures of globalization raise the demand for a practicable and learnable method for improving such a global mindset. In addition, recommendations on emerging cultural values of a globalized business environment, which are spotted by the method, may not only provide "best practice" stories, but also encourage applications of conceptual frameworks in daily management. In the light of this, it is necessary to learn more about the cultural values that would be spotted and evaluated by a global mindset improvement method in the following section. 


\section{Quan Hoang Vuong}

\subsection{Cultural Values}

Academics attempt to investigate not only how managers and institutions learn and unlearn cultural values-for instance, Berry $(1983,1997)$, Dweck (2006), Levy et al. (2007), and Vuong, Napier \& Tran (2013) —but also their influence on business performance and even social issues (Bell 1973, 1976; Inglehart 1977, 1990, 1997; Hofstede 1983; Kitayama, Markus \& Kurukawa 2000; Schwartz \& Bardi 2001; Schwart 2006).

In the 1950s and 1960s, principles of sound management were considered universal-especially in Europe and the U.S.—and nationality was ignored. Based on his 1967-1978 research on 116,000 responses of international staff of the large multinational corporation IBM from 40 countries, Hofstede (1983) argues that national and regional values are important to management because of political, sociological, and psychological reasons. Moreover, these values are difficult to change (Hofstede 1983, p.76; Lipartito 1995; Schwartz \& Bardi 2001). Hofstede first describes national cultures in four dimensions: (i) individualism vs. collectivism, (ii) large or small power distance, (iii) strong or weak uncertainty avoidance, and (iv) masculinity vs. femininity. Then, together with Michael Harris Bond and Michael Minkov, Hofstede adds long-term orientation (1991) and indulgence vs. restraint (2010) as the fifth and sixth dimensions.

By examining the relation between Hofstede's (1983) cultural dimensions and Lumpkin \& Dess's (1996) five dimensions of entrepreneurial orientation, Lee \& Peterson (2000) propose that “a society's propensity to generate autonomous, risk-taking, innovative, competitively aggressive, and proactive entrepreneurs and firms depends on its cultural foundation.” Further, Vuong et al.'s (2013) investigation of 115 individual respondents into business successes in Vietnam reveals that creativity plays a critical role in the "entrepreneurial stage" of a business's life cycle, while traditional cultural values, to a large extent, adversely affect the entrepreneurial spirit of the community (Vuong \& Tran 2009). The investigation also suggests a significant role for a multiple-filters information process of innovation.

Lipartito defines culture as "a system of values, ideas, and beliefs which constitute a mental apparatus for grasping reality" $(1995, \mathrm{p} .2)$. Therefore, business culture is "that set of limiting and organizing concepts that determine what is real or rational for management, principles that are often tacit or unconscious." When seeing the world in similar terms, sharing a common understanding of how markets operate, agreeing on what generates profits and where to invest earnings, managers may make the same decisions. In addition, corporate cultural values affect the way firms create, collect, and coordinate resources, especially knowledge and information (Nelson \& Winter 1982). In light of this, Lipartito (1995) notes that entrepreneurs have no choice but to "remake culture" in order to improve competitive capacity, and often in unexpected ways. 
Schwartz defines cultural values as "conceptions of the desirable that guide the way social actors (e.g. organizational leaders, policy-makers, individual persons) select actions, evaluate people and events, and explain their action and evaluation" (1999, p.24). Schwartz suggests that the three dimensions, (i) embeddedness vs. intellectual and affective autonomy, (ii) hierarchy vs. egalitarianism, and (iii) mastery vs. harmony help societies deal with three basic issues, namely (i) defining the nature of the relation between the individual and the group, (ii) guaranteeing responsible behavior that will preserve the social fabric, and (iii) the relation of mankind to the natural and social world. Schwartz notes that as certain cultural value orientations share assumptions, "it is easier to affirm and act on them simultaneously in a culture" (2006, p.141). He also claims that a coherent circular structure of relations among cultural values distinguishes his approach from others such as Hofstede (1983) and Inglehart (1997), who proposes tradition vs. secular-rational and survival vs. self-expression value dimensions.

While modernization theorists-including Karl Marx, who foresaw that industrialization would transform the world when publishing Das Kapital in 1867-argue that overwhelming economic and political forces drive cultural changes, their opposites assume that cultural values are relatively independent of economic condition (DiMaggio 1994). The former predicts that traditional values would be replaced by "modern" values. The latter emphasizes the persistence of traditional values. Indeed, industrialization leads to changes in gender roles, attitudes toward authority, and sexual norms, declining fertility rates, broader political participation, and a less susceptible populace. But cultural changes do not take such a simple linear path (Inglehart \& Baker 2000). Many-including Dahrendorf (1959), Bell (1973, 1976), and Inglehart (1977, 1990, 1997)—suggest that economic development has given rise to two dimensions of cross-cultural differentiation: (i) early industrialization and the rise of the working class, and (ii) affluent conditions of advanced industrial society and the rise of the service and knowledge sectors. The shift from the first to the second dimension brought changes in people's daily experiences and even worldviews (Bell 1973; Inglehart 1997). In light of this, one may expect changes in values to happen gradually when human beings enter a post-industrial society as well as the next level of development.

In a process of moving from the "game against nature" of pre-industrial life (Bell 1976, p.147) to the "game against fabricated nature" of industrial life (Bell 1973, p.147), then to the "game between persons" of post-industrial life (Bell 1973, pp.148-149), Inglehart \& Baker (2000, p.22) note that "less effort is focused on producing material objects, and more effort is focused on communicating and processing communication." In addition to Bell's $(1973,1976)$ notice of an increasingly important role of formal education and job experience in developing one's capability of "autonomous decision-making," Inglehart (1997) emphasizes the growing self-expression, especially that of service and knowledge workers. The existing cultural and 


\section{Quan Hoang Vuong}

traditional religious values influence the ways in which societies nurture or hinder the changing process (Weber [1904] 1958; Huntington 1993, 1996). Also, distinctive cultural traits endure over long periods of time and continue to shape a society's political and economic performance (Putnam 1993; Hamilton 1994; Fukuyama 1995; Inglehart \& Baker 2000). Based on empirical evidence from 65 societies, Inglehart \& Baker (2000) suggest that the emergence of new values is difficult because the values "can and do change but they continue to reflect a society's cultural heritage" (p.49). In other words, with the help of the appropriate methods, one can spot the emerging cultural values in a changing society. Naturally, cultures have huge influence to the choice of leadership, and both form a type of "ecosystem" in which subsequent processes such as innovation, resource allocation, and decision-making would later reinforce or reject the values embedded in it, in line with Kuada (2010, pp.12-13).

The acknowledgement of emerging cultural values often requires supporting evidence accumulated over long periods of time and covered by large number of countries and territories. For instance, it took Hofstede approximately 11 years (from 1967 to 1978) to collect responses from 40 countries before introducing his seminal work on four cultural dimensions in 1983. As for Schwartz (2006), it took him seven years (from 1999 with data from 49 countries to 2006 with data from 73 countries) to affirm his three dimensions of cultural values. Such practices are incredibly expensive to businesspeople. They tend to classify a cultural value into a known category. This way of classification, however, does not provide them with a framework for evaluation.

\section{Integration of Emerging Socio-Cultural Values Through Mindsponge Processes}

The above-mentioned literature review raises three research questions.

The first is, how should executives, managers, and corporations improve their global mindsets in today's changing-even faster and deeper-world? Although a mindset is rather a stable set of cultural values, it is possible to change it when its elements are removed or replaced. Indeed, people often change their minds, especially those who experience cross-cultural settings. Businesses request more than just a change: They ask for change that assures that core values and entities are strengthened while capturing emerging opportunities. In other words, the process of improving a mindset needs to be manageable. To this end, this section discusses Vuong et al.'s (2013) mindsponge as a mechanism for learning and unlearning values. The mindsponge divides consciousness into three zones based on different levels of appropriateness of values, from a nucleus of core values to a comfort zone and then to an environment of cultural values that one may respect. 
The second research question is, what are the challenges of learning and unlearning cultural values? Cultural values are difficult to change and deeply rooted in mindsets. There are so many values surrounding individuals and institutions. Just a few are accepted as core values, which identify a person or an organization. This suggests the availability of a filtering process that extracts assumingly appropriate values. Still, it is not enough. The "checks and balances" principle requests that the extracted values construct a certain level of trust. Last but not least, the inductive attitude enforces such procedures for value filtering and trust examining, repeatedly and continuously.

The third research question is, what emerging values, if any, can the mindsponge mechanism and the multi-filter information process spot in the economy of Vietnam? In addition to contributing to an understanding of transition economies, the quest for answering this question provides business executives and managers with manageable tools and practical guidance for employing a conceptual framework to deal with daily business operations.

\subsection{A Conceptual Framework Constructed by the Mindsponge and Its Underlying Theme Multi-Filter Information Process}

The mindsponge mechanism (Vuong et al. 2013) and its underlying theme of a multi-filter information process (Vuong \& Napier 2014) offer a conceptual framework to address the three research questions. Figure 8.1 divides the values that one mindset deals with into four groups.

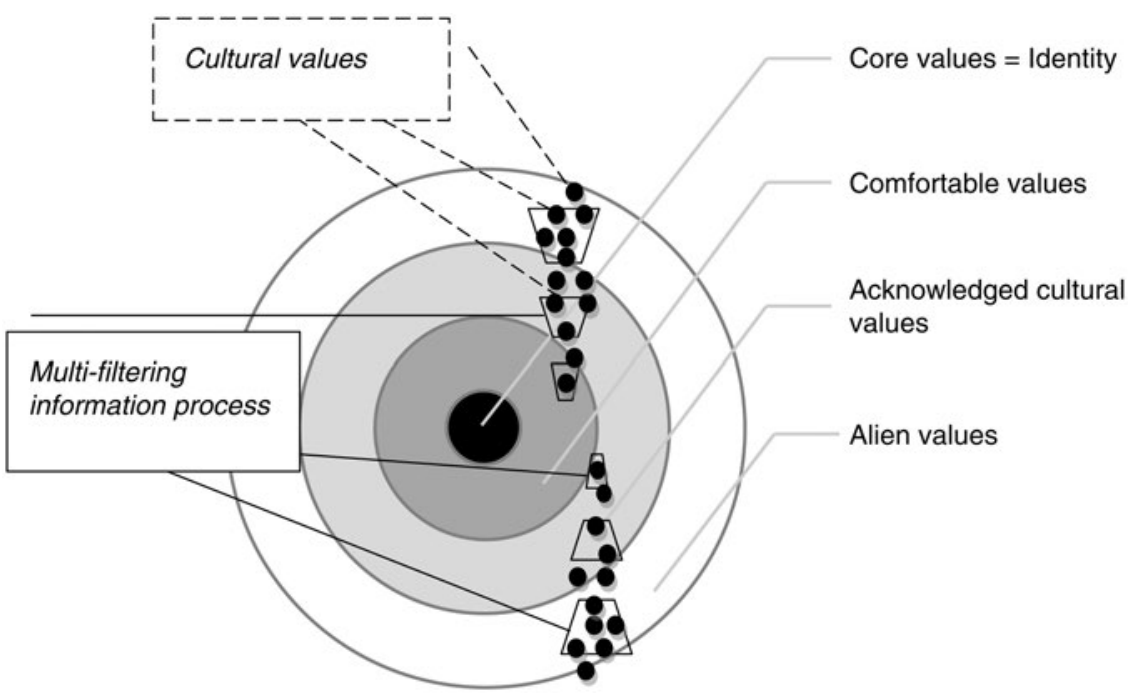

Figure 8.1 A Conceptual Framework for Spotting Values 


\section{Quan Hoang Vuong}

Alien [cultural] values are plentiful in cross-culture workplaces in today's globalized world. People may ignore their presence until some effects are acknowledged, or sometimes just out of curiosity. Those who are eager to learn about something new kick off an information multi-filtering process for sorting positive-effect values. New cultural values may enter randomly and equally, but are not digested in the same way. Only people who desire to improve their mindset try to filter out inappropriate values. The remaining values are respectable and may cause some minor changes in responses to cultural difference.

Acknowledged values that bring benefits then keep being filtered and may become comfortable values as the multi-filtering process continuously affirms their appropriateness. Let's imagine that a manager first goes to a stadium for a football game because he acknowledges the willingness of his colleagues as an effort to build team spirit. Then he realizes that such a social activity brings him not only a better understanding of his team members, but also of potential business partners and clients who are also in the fan club. Now, shouting and cheering in public and drinking after the game would comfort him.

The dark solid circle in Figure 8.1 consists of core values identifying an individual (or an institution). As a value approaches the central circle, the filter becomes tougher. Not only is a cost-benefit analysis on the acceptance of the value conducted, but also its appropriateness is compared to the existing core values. Even if the value passes the hardest test to enter the central circle, that is, to become a core value, it cannot rest.

A well-functioning mindsponge suggests one should not take any new value to heart without a systematic testing and questioning process (Vuong et al. 2013). Moreover, whenever evidence shows that the value is not as certain as it seemed, the mindset is most likely to unlearn it. This is because the more "core" the value is, the larger the risk the mindset has to be willing to take if it trusts in a "wrong" one (Mayer, Davis \& Schoorman 1995). To this end, the inductive mindsponge also conducts a reverse process for continuously testing, reconfirming, and even unlearning a value.

The mindsponge process offers businesspeople and corporations a practicable and doable framework to improve their global mindsets. Whenever they question a cultural value, the mindsponge helps them continuously evaluate it. Moreover, the mindsponge process, as a consistent analytical framework, builds their confidence in their evaluation and decision to learn or unlearn the value.

The mindsponge also suggests the most challenging thing one may face in learning and unlearning cultural values, namely, that it is a lengthy and tedious process. A new cultural value has to be acknowledged and then become comfortable before managing to enter the nucleus. The reverse is also true, as ejecting a value from the core nucleus is an equally painful process. Therefore, great patience and confidence built by the disciplined practice of an evaluation framework are necessary.

Indeed, the deployment of the mindsponge process helps spot three emerging values in the transition economy of Vietnam. The following section 
discusses the application of this conceptual framework in the Vietnamese economy, where different cultural values are struggling to find a certain place in the mindsets of people, corporations, and even society. Clashing with capitalist and Western culture provides the communist and Confucian Vietnamese with not only new values, but also opportunity for improving their global mindsets.

\subsection{Three Emerging Values in the Transition Economy of Vietnam}

The transition economy of Vietnam, which is rapidly being exposed to the global environment, is witnessing cultural changes (Napier \& Vuong 2013a). The unequal relationship between student and teacher in a Confucian society is moving toward a student-centered education. Saving up as a traditional characteristic of Vietnamese people is being replaced by consumerism, especially by the youth. Communist corporate leaders welcome Western capitalists to be strategic partners. This circumstance raises an interest in exploring emerging values that exert great influence on the country's dynamic economy.

The employment of the mindsponge and its underlying multi-filter information process to investigate the transition economy of Vietnam unveils three emerging values. They first appear at the start of various change processes. Their appropriateness is tested and reaffirmed at different states, for instance, from a close, centrally planned (in the 1990s) to an open, market-oriented economy (2000s), and toward becoming a proactive player in the world value chain (2010s). While evaluating and re-evaluating the values, change processes-such as implementing economic renovation policies and building trust from performance and capability—not only validate but also carry them into society's nucleus of core cultural values. Last but not least, the values' influence is getting greater, as they are becoming core values. In other words, the values gradually enlarge their influential space. They first influence a group of people-for instance, the entrepreneurs-then an economic sector, and finally the majority of the society.

The three are (i) serendipity as a method of innovation, (ii) pursuing creative performance, and (iii) trust as a process of building confidence and reliability. Stories learned from entrepreneurial champions who participated in a survey on corporations, including innovation capacity (Vuong, Napier, Vu, Nguyen, \& Tran 2014), help explain the concepts through real-life business experience.

\section{Serendipity: From Loan-Seeking to a Method of Innovation}

Relationship-based loan seeking is a typical Confucian behavior in Vietnam (Vuong \& Tran 2009). Although relationships play a critical role in business development everywhere, its color in East Asian cultural settings is quite different from the West. Confucianism not only advocates a social hierarchy, but also imposes moral and cultural norms for guiding behaviors. 


\section{Quan Hoang Vuong}

On financing business operations, for instance, the relationship between banks and entrepreneurs, even private businesses, is typically unequal. It is a popular notion that borrowing entrepreneurs are "asking for favors," for which bankers hold the overwhelming right to "giving decisions." In such circumstances, a decisive factor is bankers' knowing "who the entrepreneurs are" rather than "what capacity the entrepreneurs possess." This personal trust-based credit transaction, perhaps, shows the most apparent manifestation of the Confucian value of the unequal social relationship. The same holds true for credit transactions. It is common that when they have "good" relationships with the entrepreneurial borrowers, bankers can, on behalf of the borrowers, prepare loan documents. Both lenders and borrowers believe that this is part of the caretaking element in their trust-based relationship, partly reflecting the benevolence that has been highly advocated in Confucianism.

Loan seeking also results in the manipulation of interest groups and monopolists (Vuong 2014a). In the state-led economic model of Vietnam, corruption is rampant and accompanied by crony capitalism. For example, despite loss-making performances, poorly drafted projects, and paramount losses, state-run conglomerate Vinashin was able to borrow a multi-billion U.S. dollars loan to fund its operations and purchase broken ships from abroad at sky-high prices. The large differences in market price and reported price went into the pockets of the management. Vinashin was financed by ten local banks and international lenders. After its insolvency, the Vietnamese government guaranteed the issue of Vinashin bonds in Singapore to pay for its debt. In addition, the local bank HBB, which lost U.S. \$200 million by lending to Vinashin, was allowed to be acquired by the Vietnamese privately run SHB. The acquisition was regarded as an alternative solution to clear Vinashin's debt with HBB.

The lack of genuine entrepreneurs results in mimicking investment concentration and business models-for instance, in the two years 2005 and 2007, 10 rural commercial banks were acquired by private traders, then upgraded to joint stock commercial banks, then expanded to include financial services such as securities and insurance. To escape from considering cost and benefit, verifying industry outlook, and examining management capability, the managers focused on increasing the chance of meeting serendipity by trying to enrich information inputs and quickly make decisions on any spotted opportunity. Here, it is noteworthy that valuable information is worthless when methods to digest it are absent. A systematic process is necessary to transform insights and creative ideas into new products, services, and solutions.

Also pursuing extraordinary, unintentional, or undiscovered business outcomes, entrepreneurs who tap serendipity, which is the ability to notice, evaluate, and take advantage of unexpected information better or faster than competitors, may build or develop this as an advantage. Napier \& Vuong (2013b) argue that serendipity is not serendipitous. The former is a 
method of making creativity. The latter describes the unexpected exploration of an opportunity that seemingly appears out of the blue. Serendipity-as a method of creativity-offers innovation capacity improvement by increasing awareness of the existence of unlooked-for but valuable possibilities that can enhance the global mindset. For example, experiencing international distribution and learning from what people do in foreign countries help an entrepreneur realize an "idle" opportunity at home.

When the founders of Phu Le Wine Co. returned to their hometown, the winemaking couple planned some quiet time after their child's birth. During that time, they visited the village of Phu Le, famous for its traditional rice wine, and spotted an opportunity. Despite brand popularity and good quality, the Phu Le wine production was fragmented and unorganized. Almost every household in the village produced wine. Every producer claimed his/her wine to be the best. And the best wine producer was unable to make wine production commercially viable because of an unstable and insufficient supply. Phu Le Wine Company was founded to unite household wine producers and educate them on food safety awareness and standards. Four years later, Phu Le's sales reached U.S. \$2 million. More importantly, more than $30 \%$ of the Phu Le commune population now works for the firm. By seeing a bigger picture, by thinking more "globally," or at least regionally, the couple was able to make a difference and help others see differently as well.

Exploiting serendipity works under certain conditions, as Figure 8.2 suggests. There is always an abundance of information suggesting chances of creating a new business in the economy and marketplaces. Also, there are available people who are capable of running a business. Only when the market prospect is appropriate for the person's preference and entrepreneurial orientation is a starting combination of some new business acknowledged.

Next, the combination goes into a multi-filtering process, which scans for the most useful insights in different disciplines, then tries to integrate various insightful dots into an innovation of a new product/service, new management process, or new business model. A "permanent bank"-which consists of understanding management theories, the global market situation, and experience of living and working in a multicultural environment, in conjunction with entrepreneurial alertness and risk tolerance, help entrepreneurs evaluate their readiness to move from the "observed" insights to a valuable innovation in the marketplace.

Then the mindsponge helps the entrepreneur evaluate the innovation and make a business decision. If the innovation is appropriate to the entrepreneur's core values, then the decision is "GO." It is noteworthy that the serendipity maker is able to see both value in the information and potential opportunity, but also to see and connect (odd) dots. The more dots the serendipity maker spots, the better he/she becomes at evaluating opportunities. The more efficiently he/she connects the dots, the better he/she is at detecting missing points. 


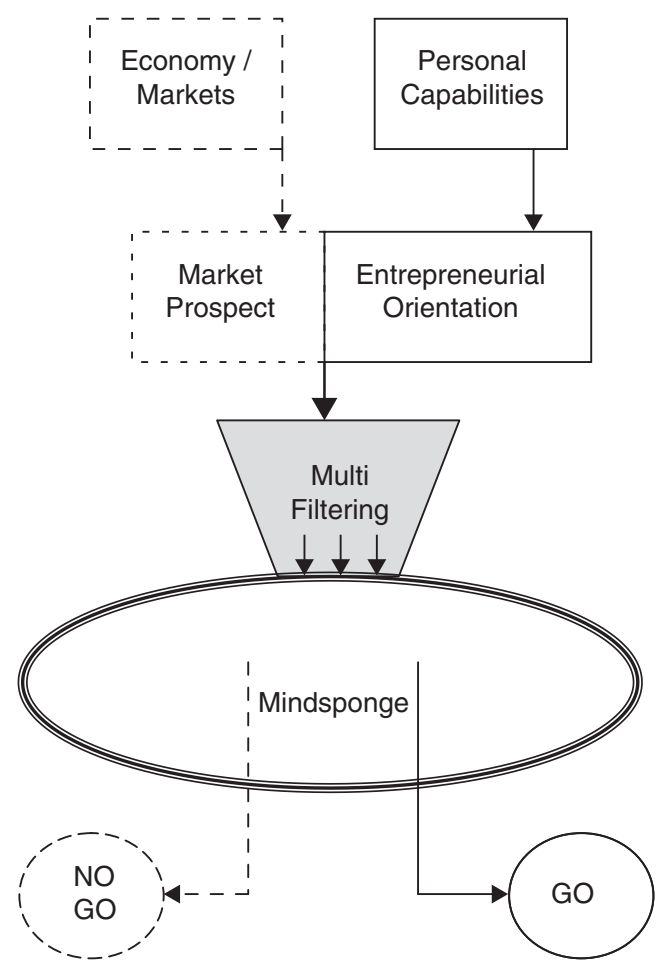

Figure 8.2 Information Process of Serendipity

\section{Creative Performance: From Value Creation to Innovation}

When economic renovation policies were introduced to the Vietnamese economy in the late 1980s, quality of goods and services were a strange concept, as arm's length transactions rarely occurred in a centrally planned economy. The voice of consumers, if any, had been very low when distribution and consumption targets were planned by the central government. Producers and manufacturers, therefore, had paid no attention to users, a word that better describes the circumstance than "consumers." The Renovation (famously known as "Doi Moi") did make changes, not only in economic performance, but also in the minds of the country's political figures (Heberer \& Kohl 1999; Vuong, Dam, Van Houtte, \& Tran 2011). Economic crisis and harsh reality were neither necessary nor sufficient conditions for such changes to take place. Heberer \& Kohl (1999) point out that the changes in the structure of property rights, which resulted in an emergence of a new economic elite of private entrepreneurs, were accompanied by a change of the value system. Changing social and political values constituted a partial weakening of the economic and political power of the central government that then drove political change. Entrepreneurial elements-for instance, the 
willingness to create value-prompted consideration of structural changes and emerging opportunities, and then laid down cornerstones of policies and innovation (Vuong et al. 2011). It is noteworthy here that when the multi-filtering system sparked, the mindsponge started working.

In an exploratory survey of 40 firms about their innovative capacity (the i2Metrix, Vuong et al.2014), the leaders of all of the surveyed firms reported experiencing major shifts in their cultural settings and beliefs due to changes in social ideologies, business modalities (e.g., moving from a market economy in the southern part of Vietnam during the American War to a purely socialist economy and then back to a more market-oriented one), or form of enterprise (e.g., moving from being a traditional state-owned enterprise to a privatized one). They were also able to give examples of the mindsponge process in their organizations, even though they were unfamiliar with the term. For instance, the corporate leaders acknowledged that they need to build subordinates' confidence in their leading competence, which is proved by improvements in business performance. Such effort-which is likely affected by Western leadership-is certainly not a norm in a Confucian hierarchy, where subordinates should obey superiors.

The concept of innovation, moreover, is developed further to include responsible creativity as a cultural value driving economic growth, as illustrated by the "Vietnamese Coffee King" Dang Le Nguyen Vu (Napier 2012; Schatz 2012). That is, pursuing innovation is not for corporate earnings, but to create harmony and sustainable prosperity. Meanwhile, Chairwoman $\mathrm{Vu}$ Thi Thuan of Traphaco (a pharmaceutical manufacturer) insisted that replacing hundreds of workers with automated production lines was not an innovation. Her firm must not only secure jobs for loyal workers, but also provide a stable income source to their families. Traphaco's innovation efforts, therefore, focus on smarter and friendlier marketing and distribution as the firm is serving special clients: the patients.

\section{Trust: From Intuitive Awareness to Cost-Benefit Analysis and Multi-Filtering Process}

Trust in the Confucian society of Vietnam means a relationship in which one can entrust their work to the hands of someone that he/she knows and is confident about (Vuong \& Tran 2009, p.74). In other words, "who the guy is" outweighs "what the guy is doing and capable of." In this social setting, trust easily turns into a personal matter, even in institutional transactions. That is, if you do not accept an offer by your friend, then the friend will interpret your refusal to mean you do not trust your friend (to give you a good deal), and finally your friendship will most likely be broken. Such social pressure may lead to business mistakes.

Fortunately, entrepreneurs think differently in order to pursue creative performance. As the mindsponge suggests, a new value has to go through a process of information multi-filtering and trust evaluating, which may 


\section{Quan Hoang Vuong}

yield a better performance and higher profits. When receiving an idea for a new product or a proposal for a new business model, they make a decision to approve or refuse based on technological feasibility and commercial viability, not friendship, loyalty, or family relation (Vuong et al. 2014). Indeed, as cost-benefit analysis becomes popular-perhaps, as a result of increasing numbers of MBA graduates and lessons learned from the business practices of multinational corporations in Vietnam-the solidity of a business relation now depends on how benefits are allocated among business partners.

Lewicki \& Bunker (1996) have developed a three-stage process of trust. The first stage is calculus based, assessing cost-benefit considerations. The second is knowledge-based trust that relies on information rather than deterrence, and develops over time with increasing interaction among individuals. The last stage is identification based, when trust matches or comes in sync with another person's desires and intentions. While there is significant overlap between the stages, an expectation of a continuous relationship suggests a high level of trust (Paliszkiewicz 2011).

\section{Closing Remarks}

The concept of mindsponge provides executives, managers, and organizations with not only a practical framework for improving their global mindset by identifying and strengthening core values, but also capturing emerging opportunities. In today's fast-changing world, globalization and the Internet revolution provide businesspeople with abundant information. The mindsponge and its underlying theme of multi-filtering help them overcome the challenge of the information flood by considering only appropriate values and worthy opportunities (Vuong \& Napier 2014). Also, great patience should be acknowledged in any change process, as learning and unlearning cultural values are tedious, lengthy, and even painful.

In addition, a disciplined information process makes it possible to catch even short-lived ideas and opportunities-which are consequences of Friedman's (2005) "flat world"-with a serendipity-based method of creativity (Napier \& Vuong 2013b). When approaching the mindset of core values or getting business decisions to move forward, the value or opportunity has to convince a trust guard whose inductive attitude is getting more suspicious of its "appropriateness" and "worth." A reverse flow is to eject a waning value existing in the mindset or to stop an ongoing business.

Efforts to introduce the mindsponge and its workhorse multi-filtering information process to the business community through the corporate inclusive innovation capacity survey resulted in uncovering three emerging values in the transition economy of Vietnam. The three are (i) seeking serendipity as a method of innovation, (ii) pursuing creative performance, and (iii) building trust with the multi-filtering process. Here, a well-functioning mindsponge 
plays the role of not only an explorer, but also a judge enforcing the "checks and balances" principle.

For instance, while entrepreneurs acknowledge that innovation capacity largely defines the destiny of entrepreneurial endeavors, most of them do not realize that only a small percentage of innovations have been adopted into industrial commercialization and of these, only a small percentage of adopted innovations have reaped financial payoffs. Firms should also beware of abusing innovation. Scrambling for innovation may cause an entrepreneurial curse of innovation (Maddock 2013). Innovation per se does not determine the success of an innovating firm. The market does. Overexcitement about innovation cannot replace an appropriate methodology of organizing the business process, disciplines for pursuing desired outcomes, and tools/techniques for measuring the efficiency as well as the effectiveness of such important, and oftentimes tricky, pursuits (Vuong 2014b).

\section{Note}

1. Acknowledgement: The author sincerely thanks Dr. Nancy K. Napier (Boise State University, Idaho, U.S.), Dr. Dolly E. Samson (Stamford International University, Bangkok, Thailand), and Tran Tri Dung (DHVP Research, Hanoi, Vietnam) for the insightful discussions and suggestions for improvements.

\section{References}

Bartlett, CA, \& Ghoshal, S 1989, Managing Across Borders: The Transnational Solution (Vol. 1). Boston, MA: Harvard Business School Press.

Bell, D 1973, The Coming of Post-Industrial Society. New York: Basic Books.

Bell, D 1976, The Cultural Contradictions of Capitalism. New York: Basic Books.

Berry, JW 1983, 'Acculturation: A comparative analysis of alternative forms', in Samuda, RJ \& Woods, SL (Eds.), Perspective in Immigrant and Minority Education (pp.66-77). Lanham, MD: University Press of America.

Berry, JW 1997, 'Immigration, acculturation, and adaptation,' Applied Psychology: An International Review, vol.46, no.1, pp.5-68.

Boyd, R \& Richerson, P 1985, Culture and the Evolutionary Process. Chicago, IL: University of Chicago Press.

Caproni, PJ, Lenway, SA \& Murtha, TP 1992, Multinational Mind Sets: Sense Making Capabilities as Strategic Resources in Multinational Firm. Division of Research, School of Business Administration, University of Michigan. http://141.213.232. 243/bitstream/handle/2027.42/35479/b1579411.0001.001.txt

Chandler, AD 1962, Strategy and Structure. Cambridge, MA: MIT Press.

Dahrendorf, R 1959, Class and Class Conflict in Industrial Society. Stanford, CA: Stanford University Press.

DiMaggio, P 1994, 'Culture and economy' in Smelser, NJ \& Swedberg, R (Eds.), The Handbook of Economic Sociology. Princeton, NJ: Princeton University Press, pp.27-57.

Doz, YL, \& Prahalad, CK 1991, 'Managing DMNCs: A search for a new paradigm,' Strategic Management Journal, 12(S1), pp.145-164.

Dweck, CS 2006, Mindset: The New Psychology of Success. New York, NY: Random House. 


\section{Quan Hoang Vuong}

Evans, P, Pucik, V, \& Barsoux, JL 2002, The Global Challenge: International Human Resource Management. London, UK: McGraw-Hill.

Florida, R 2005, 'The world in number: The world is spiky', The Atlantic Monthly, October, 296(3): pp.48-51.

Friedman, LT 2005, The World Is Flat. New York, NY: Farrar, Straus and Giroux.

Fukuyama, F 1995, Trust: The Social Virtues and the Creation of Prosperity. New York, NY: Free Press.

Goldstein, S \& Brooks, R 2007, Understanding and Managing Children's Classroom Behavior: Creating Sustainable, Resilient Schools. New York, NY: John Wiley and Sons.

Gupta, AK \& Govindarajan, V 2002, 'Cultivating a global mindset,' Academy of Management Executive, vol.16, no.1, pp.116-126.

Hamilton, GG 1994, 'Civilization and organization of economies,' in Smelser, NJ \& Swedberg, R (Eds.), The Handbook of Economic Sociology (pp.183-205). Princeton, NJ: Princeton University Press.

Heberer, T \& Kohl, A 1999, 'Private entrepreneurship and social change in transitional economies: The sociopolitical impact of private industry in Vietnam,' The Private Economy in China and Vietnam and Its Economic, Social, and Political Consequences.

Hofstede, G 1983, 'The cultural relativity of organizational practices and theories,' Journal of International Business Studies, vol.14, no.2, pp.75-89.

Hofstede, G, \& Minkov, M 2010, 'Long-versus short-term orientation: new perspectives,' Asia Pacific Business Review, vol. 16, no. 4, pp.493-504.

Huntington, SP 1993, 'The clash of civilizations?' Foreign Affairs, vol.72, no.3, pp.22-49.

Huntington, SP 1996, The Clash of Civilizations and the Remaking of World Order. New York: Simon and Schuster.

Inglehart, R 1977, The Silent Revolution: Changing Values and Political Styles in Advanced Industrial Society. Princeton, NJ: Princeton University Press.

Inglehart, R 1990, Culture Shift in Advanced Industrial Society. Princeton, NJ: Princeton University Press.

Inglehart, R 1997, Modernization and Post-Modernization: Cultural, Economic, and Political Change in 43 Societies. Princeton, NJ: Princeton University Press.

Inglehart, R \& Baker, EW 2000, 'Modernization, cultural change, and the persistence of traditional values,' American Sociological Review, vol.65, pp.19-51.

Kitayama, S, Markus, HR, \& Kurokawa, M 2000, 'Culture, emotion, and well-being: Good feelings in Japan and the United States,' Cognition \& Emotion, vol. 14. no. 1 , pp. 93-124.

Kuada, J 2010, 'Culture and leadership in Africa: A conceptual model and research agenda,' African Journal of Economic and Management Studies, vol.1, no.1, pp.9-24.

Lee, MS \& Peterson, JS 2000, 'Culture, entrepreneurial orientation, and global competitiveness,' Journal of World Business, vol.35, no.4, pp.401-416.

Levy, O, Beechler, S, Taylor, S \& Boyacigiller, NA 2007, 'What we talk about when we talk about "global mindset": Managerial cognition in multinational corporations,' Journal of International Business Studies, vol.38, no.2, pp.231-258.

Lewicki, RJ \& Bunker, BB 1996, 'Developing and maintaining trust in work relationships,' in Kramer, RM \& Tyler, TR (Eds.), Trust in Organizations, Frontiers of Theory and Research (pp.114-139). Thousand Oaks, CA: Sage.

Lipartito, K 1995, 'Culture and the practice of business history', Business and Economic History, vol.24, no.2, pp.1-41.

Lumpkin, GT, \& Dess, GG 1996, 'Clarifying the entrepreneurial orientation construct and linking it to performance,' Academy of Management Review, vol. 21, no. 1, pp.135-172. 
Maddock, M 2013, 'Invention: The entrepreneurial curse,' Forbes, May 15.

Mayer, RC, Davis, JH, \& Schoorman, FD (1995). An integration model of organizational trust. Academy of Management Review, 20(3), pp.709-734.

Maznevski, M \& Lane, H 2007, 'Shaping the global mindset: Designing educational experiences for effective global thinking and action', in Muzychenko, $\mathrm{O}$ (Ed.), Facilitating International Entrepreneurship through Developing a Global Mindset. Glasgow, Scotland: Institute for Small Business and Entrepreneurship, pp.171-184.

Muzychenko, O 2007, Facilitating International Entrepreneurship through Developing a Global Mindset. Glasgow, Scotland: Institute for Small Business and Entrepreneurship.

Napier, NK 2012, 'What's small, tasty and may change the world? The yin and yang of responsible creativity,' Psychology Today, <http://www.psychologytoday.com/ blog/creativity-without-borders/201205/whats-small-tasty-and-may-changethe-world>

Napier, NK \& Vuong, QH 2013a, What We See, Why We Worry, Why We Hope: Vietnam Going Forward. Boise, ID: Boise State University CCI Press.

Napier, NK \& Vuong, QH 2013b, 'Serendipity as a strategic advantage,' in Wilkinson, TJ (Ed.), Strategic Management in the 21st Century; Volume 1: The Operational Environment (pp.175-199). Westport, CT: Praeger/ABC-Clio.

Nelson, R \& Winter, S 1982, An Evolutionary Theory of Economic Change. Cambridge, MA: Harvard University Press.

Paliszkiewicz, JO 2011, 'Trust management: Literature review,' Management, vol.6, no.4, pp.315-331.

Pisapia, J, Reyes-Guerra, D \& Coukos-Semmel, E 2005, 'Developing the leader's strategic mindset: Establishing the measures,' Leadership Review, vol.5, no.1, pp.41-68.

Prahalad, CK \& Bettis, RA 1986, 'The dominant logic: A new linkage between diversity and performance,' Strategic Management Journal, vol.7, pp.485-501.

Putnam, R 1993, Making Democracy Work: Civic Traditions in Modern Italy. Princeton, NJ: Princeton University Press.

Rhinesmith, SH 1992, 'Global mindsets for global managers,' Training and Development, vol.46, no.10, pp.63-69.

Rhinesmith, SH 1993, Globalization: Six Keys to Success in a Changing World. Alexandria, VA: The American Society for Training and Development.

Rhinesmith, SH 1996, A Manager's Guide to Globalization: Six Skills for Success in a Changing World (2nd Ed.). New York, NY: McGraw-Hill.

Schatz, R 2012, 'Culture and values as keys to economic growth,' Vietnamica, <http:// www.vietnamica.net/culture-and-values-as-keys-to-economic-growth/>

Schwartz, SH 1999, 'A theory of cultural values and some implications for work,' Applied Psychology: An International Review, vol.48, no.1, pp.23-47.

Schwartz, SH 2006, 'A theory of cultural value orientations: Explication and applications,' Comparative Sociology, vol.5, no.2/3, pp.137-182.

Schwartz, SH \& Bardi, A 2001, 'Value hierarchies across cultures: Taking a similarities perspective,' The Journal of Cross Cultural Psychology, vol.32, no.3, pp.268-290.

Taylor, WE 1991, 'The logic of global business: An interview with ABB's Percy Barnevik,' Harvard Business Review, vol.69, no.2, pp.93-105.

Vuong, QH 2014a, 'Vietnam's political economy: A discussion on the 1986-2016 period,' Working Papers CEB, N¹4-010, Université Libre de Bruxelles.

Vuong, QH 2014b, 'The harsh reality of pursuing innovations: Emerging market perspectives,' Proceedings of the 2nd National Conference on Management and Higher Education Trends \& Strategies for Management and Administration, Oct. 31-Nov. 1, Stamford International University, Bangkok, Thailand. 


\section{Quan Hoang Vuong}

Vuong, QH, Dam, VN, Van Houtte, D \& Tran, TD 2011, 'The entrepreneurial facets as precursor to Vietnam's economic renovation in 1986,' The IUP Journal of Entrepreneurship Development, vol.8, no.4, pp.6-47.

Vuong, QH, \& Napier, NK 2013, 'Anatomy of the 3D innovation production with the Cobb-Douglas specification,' Sociology Study, vol. 3, no. 1, pp.69-78.

Vuong, QH \& Napier, NK 2014, 'Making creativity: The value of multiple filters in the innovation process,' International Journal of Transitions and Innovation Systems, vol.3, no.4, pp.294-327.

Vuong, Q. H. \& Napier, N. K. 2015, 'Acculturation and global mindsponge: An emerging market perspective,' International Journal of Intercultural Relations, 49, pp.354-367.

Vuong, QH, Napier, NK \& Tran, TD 2013, 'A categorical data analysis on relationships between culture, creativity and business stage: The case of Vietnam,' International Journal of Transitions and Innovation Systems, vol.3, no.1, pp.4-24.

Vuong, QH, Napier, NK, Vu, KH, Nguyen, MC \& Tran, TD 2014, 'Measuring corporate innovation capacity: Experience and implications from i2Metrix implementation in Vietnam, ASEAN Journal of Management and Innovation, vol.1, no.1, pp.1-17.

Vuong, QH \& Tran, TD 2009, 'The cultural dimensions of the Vietnamese private entrepreneurship,' The IUP Journal of Entrepreneurship Development, vol.6, no.3/4, pp.54-78.

Weber, M [1904] 1958, The Protestant Ethic and the Spirit of Capitalism. [Translated by Parsons, T.] Reprint, New York: Charles Scribner's Sons. 